\title{
Associations of adverse childhood experiences and bullying on physical pain in the general population of Germany
}

This article was published in the following Dove Press journal: Journal of Pain Research

\author{
Rebecca C Brown ${ }^{1, *}$ \\ Paul L Plener ${ }^{1,2, *}$ \\ Elmar Braehler ${ }^{3,4}$ \\ Joerg M Fegert ${ }^{1}$ \\ Markus Huber-Lang ${ }^{5}$ \\ 'Department of Child and Adolescent \\ Psychiatry/Psychotherapy, University \\ of Ulm, Ulm, Germany; ${ }^{2}$ Department \\ of Child and Adolescent Psychiatry, \\ Medical University of Vienna, \\ Vienna, Austria; ${ }^{3}$ Department \\ of Psychosomatic Medicine and \\ Psychotherapy, University Medical \\ Center of The Johannes Gutenberg \\ University of Mainz, Mainz, Germany; \\ ${ }^{4}$ University of Leipzig, Department \\ of Medical Psychology and Medical \\ Sociology, Leipzig, Germany; ${ }^{5}$ Institute \\ of Clinical and Experimental Trauma- \\ Immunology, University of Ulm, Ulm, \\ Germany
}

*These authors contributed equally to this work
Correspondence: Rebecca C Brown Department of Child and Adolescent Psychiatry/Psychotherapy, University of Ulm, Steinhoevelstr. 5, Ulm 89075, Germany

Tel +49 73I 50061635

Fax +4973150061665

Email rebecca.brown@uniklinik-ulm.de
Background: Chronic pain is a frequent burden in the general population. Child maltreatment and bullying are risk factors for the development of chronic pain. Aim of this cross-sectional study was to investigate the association of child maltreatment and bullying and pain experiences in a representative sample of the general population.

Materials and methods: A total of $\mathrm{N}=2,491$ people from the general population of Germany participated in the study $\left(\mathrm{M}_{\text {age }}=48.3\right.$ years $[\mathrm{SD}=18.2], 53.2 \%$ female). Child maltreatment was assessed with the Childhood Trauma Questionnaire (CTQ), pain was rated with the Polytrauma Outcome (POLO)-physical state domain, depression scores were assessed with the Patient Health Questionnaire, and anxiety scores via the General Anxiety Disorder Questionnaire. Regression analyses were calculated to investigate the effect of bullying and child maltreatment, as well as depression, anxiety, and gender on pain experiences.

Results: A significant correlation between increasing pain levels and number of adverse childhood experiences was found. With regard to specific types of maltreatment, largest effect sizes were found for emotional abuse. Bullying was significantly, but overall rather moderately, related to pain suffering. In women, all forms of maltreatment were associated with pain, while in men only sexual and physical abuse revealed significant effects. Although depression and anxiety scores were significantly associated with the experience of current pain, they did not change the effect of child maltreatment on pain significantly.

Conclusion: In this sample of the general population, adverse childhood experiences were significantly associated with pain and showed cumulative effects, over and above depressive and anxiety symptoms.

Keywords: child maltreatment, adulthood, depression, anxiety

\section{Introduction}

Chronic pain is frequently reported in samples of the general population. In a largescale study involving 15 European countries and Israel, around 19\% of the adults reported at least a moderate to severe intensity of chronic pain. ${ }^{1}$ In general, pain can be perceived as the body's warning signal when there is an imminent threat for "actual or potential tissue damage". ${ }^{2}$ It is widely acknowledged that pain has somatosensory as well as affective compounds, ${ }^{3}$ and it has been shown that early life stressors affect neural pathways involved in the processing of acute as well as chronic pain. ${ }^{3}$

The development of chronic pain in relation to childhood maltreatment may already start in childhood or adolescence, ${ }^{4-8}$ but might also lead to adult onset of chronic pain conditions. ${ }^{9}$ Besides clinical chronic pain conditions, participants from community 
samples reporting the experience of abuse, neglect, or other traumatizing events were more likely to experience pain. ${ }^{10-13}$

Studies have also shown differential effects following diverse types of maltreatment on chronic and acute pain in different parts of the body. ${ }^{9,14,15}$ However, it has to be kept in mind that different forms of childhood maltreatment often co-occur. ${ }^{16,17}$ Therefore, several studies have focused on a "dose-response-effect," showing a positive association of the number of reported forms of childhood maltreatment or the severity of maltreatment and the likelihood or severity of chronic pain conditions. ${ }^{18-21}$

Considering possible traumatic events throughout childhood and adolescence, bullying also has to be taken into account. It has been shown that besides childhood maltreatment by family members, bullying by peers can also lead to more experiences of physical pain (chronic and acute) later in life..$^{22,23}$

Several factors may mediate the relationship between adverse childhood experiences and the development of pain. Gender can affect the hypothalamic-pituitary-adrenal axis responsiveness, rates of circuitry maturation, and neuroimmune development (for review see Ganguly and Brenhouse $^{24}$ ), all of which are involved in the processing of stress and linked to the development of chronic pain. Several studies have also shown the involvement of neuroanatomical reorganization, neurotrophin and monoamine depletion, neuroinflammation, and changes in the endocannabinoid system to link depression to the experience of pain. ${ }^{25}$

As both childhood maltreatment and different pain conditions have been associated with depression and anxiety symptoms in several independent studies, ${ }^{26,27}$ the experience of those symptoms may have had a mediating effect on the results of the current study. Therefore, analyses were controlled for both, the experience of depression and anxiety symptoms.

To our knowledge, the current study is the first to assess the cumulative effect of childhood maltreatment on the experience of bodily pain in the general population of Germany, disentangle the effect of different forms of adverse experiences (including bullying) on different types of pain (ie, overall pain, headaches, and back/neck-pain), differentiate results by gender, and to control for depressive and anxiety symptoms.

\section{Materials and methods}

Using a random route procedure, a representative sample of the German population was acquired by a demographic consulting company (USUMA, Berlin, Germany) between
September 2016 and November 2016. Households of every third residence in a randomly chosen geographical area were invited to participate in the study. In multi-person households, participants were randomly selected using a Kish selection grid. Inclusion criteria were a minimum age of 14 years and sufficient knowledge of the German language. Of 4,902 designated addresses, 2,510 households participated in the study. Non-participating households did not differ significantly from participating households with regard to all tested demographic variables, eg, geographical areas or composition of the household in terms of age and gender. Responses were anonymous. In a first step, sociodemographic information was gathered in an interview format by research staff. All other information was obtained via paper and pencil questionnaires, with research staff being available for questions.

The study was conducted in accordance with the Declaration of Helsinki and fulfilled the ethical guidelines of the International Code of Marketing and Social Research Practice of the International Chamber of Commerce and of the European Society of Opinion and Marketing Research. All participants (and if applicable their caregivers) gave written informed consent. The study was approved by the ethics committee of the Medical Department of the University of Leipzig.

\section{Measures}

The prevalence of five types of child maltreatment was assessed using the 28-item brief version of the Childhood Trauma Questionnaire (CTQ). ${ }^{28,29}$ The CTQ is a screening measure for the assessment of maltreatment in childhood and adolescence up to the age of 18 years. It contains five subscales, each assessed by five items: sexual, emotional and physical abuse as well as emotional and physical neglect. Additionally, three items assessed whether participants tend to trivialize problematic experiences within their family. Each item is rated on a scale from 1 (minimal) to 5 (severe). Therefore, sum scores from 5 to 25 can be reached on each subscale. Good psychometric properties of the German version of the CTQ were demonstrated by Klinitzke et al, ${ }^{28}$ with internal consistencies ranging between 0.62 and 0.96 for all subscales. The intra-class coefficient for an interval of 6 weeks was 0.77 for the overall scale and for subscales between 0.58 and 0.81 . Based on norm data by Häuser et al, ${ }^{30}$ severity scores for each subscale can be calculated (based on the sum scores of each subscale), ranging from "none-minimal", "minimal-moderate", "moderate-severe", to "severe-extreme". Dichotomous scores (eg, experience of 
emotional neglect: yes/no) were based on scores reaching at least moderate-severe level, as is common practice in studies using the CTQ (for details see Häuser et $\mathrm{al}^{30}$ )

Bullying was assessed with one question ("when you were a child, were you bullied at school?").

Pain was assessed using the PRE-Status module of the Polytrauma Outcome Chart (POLO-Chart) ${ }^{31}$ The POLO-Chart was designed to assess level of functioning and quality of life in patients after severe physical trauma and provides a validated tool with good acceptance among patients for the assessment of pain. The PRE-Status module assesses levels of pain before the trauma; in the current study, levels of current pain were assessed. Participants rated on a scale from 0 (not at all) to 10 (unbearable) how much they had felt pain within the past 7 days in the following parts of the body: head, neck, shoulder/upper arm, elbow/lower arm, wrist/hand, fingers, chest, stomach, spine (back), pelvis, hip/thigh, knee/shin/calf, ankle/foot, and toes. In order to be able to conduct meaningful analyses, body regions were comprised and the following scales were analyzed: "any pain"=mean of all body regions, "headache"=head, "neck/ back"=mean of neck and spine, "bodily pain" mean of all body regions except head, neck, and spine.

Depressive symptoms were assessed with the German version of the screening tool Patient Health Questionnaire (PHQ-2), focusing on the depressive symptoms "low mood" and "loss of interest". Scores can reach values from 0 to 6 , with a cutoff of values higher than 3 leading to values of sensitivity of $87 \%$ and specificity of $78 \%$ for major depression. ${ }^{32}$ Anxiety symptoms were screened for using the General Anxiety Disorder Questionnaire (GAD-2). Like the PHQ-2, the questionnaire consists of two items, with possible values from 0 to 6 and a cutoff of 3 . This cutoff is sensitive for screening for generalized anxiety disorders (86\%), panic disorders (76\%), social anxiety disorder (70\%) and moderately for PTSD $(59 \%)$. It is specific for all four types of anxiety disorders $(81 \%-83 \%)$, with an internal consistency of Cronbach's alpha $=0.82 .{ }^{33}$

\section{Participants}

Of all originally included participants $(\mathrm{N}=2,510), 19$ did not complete the POLO-Chart. The remaining 2,491 participants were aged $\mathrm{M}=48.3$ years on average $(\mathrm{SD}=18.2$, ranging from 14 to 94$)$, and $53.2 \%(\mathrm{~N}=1,324)$ were females. Almost all participants $(\mathrm{N}=2,410,96.7 \%)$ were of German nationality, $21.7 \%(\mathrm{~N}=541)$ had a secondary school degree qualifying to enter university (Abitur), while $2.2 \%(\mathrm{~N}=55)$ did not have a high-school degree and 5.2\% ( $\mathrm{N}=129)$ were unemployed. Around half of all participants $(54.6 \%, \mathrm{~N}=1,360)$ reported to be living with a partner. There were no significant gender differences with regard to general demographic variables.

\section{Statistical analyses}

Statistical analyses were performed using SPSS version 21. Gender differences regarding pain scores and adverse childhood experiences were calculated using $t$-tests and chi $^{2}$-tests. In order to analyze the cumulative effect of child maltreatment on pain, Pearson correlations were calculated. Differential effects of different types of child maltreatment and bullying on different types of pain (eg, head/neck pain, bodily pain) were analyzed using separate $t$-tests and effect sizes (Cohen's $d$ ) were calculated ( $d \geq 0.2$ small effect, $d \geq 0.5$ medium effect, $d \geq 0.8$ large effect). All variables assessing child maltreatment and bullying were entered into a regression model. Scores of the GAD-2, PHQ-2, as well as age and gender were entered as covariates to the model in order to differentiate the effect of different types of maltreatment and bullying, and to control for depressive and anxiety symptoms, age, and gender. Subsequently, in order to differentiate results by gender, separate regression analyses by gender (including the same variables as already mentioned) were calculated and presented in a separate table.

\section{Results}

Overall levels of pain were rather low $(\mathrm{M}=0.82, \mathrm{SD}=1.07)$, given a possible range of $0-10$. Relatively speaking, levels of pain were highest in neck/back or headaches. Concerning adverse childhood experiences, physical and emotional neglect were endorsed most often $(22.4 \%$ and $13.1 \%$, respectively), while having been bullied at school was least common $(10.9 \%)$. Over $30 \%$ of the overall sample reported at least one form of maltreatment or neglect of moderate to severe level, and $1.2 \%$ reported all five forms of abuse and neglect (for further details see Table 1).

\section{Cumulative effect of childhood abuse and neglect}

The number of experienced forms of childhood abuse and neglect was significantly correlated with overall pain scores ( $r=0.32, P<0.001$, Figure 1). This effect was also significant for bodily pain $(r=0.33, P<0.001)$, back/neck pain $(r=0.22$, $P<0.001)$, and headaches $(r=0.16, P<0.001)$.

\section{Differential effects of different adverse childhood experiences}

Results were significant for all forms of childhood abuse and neglect and for having been bullied by peers. This was true for 
Table I Level of reported pain and adverse childhood experiences

\begin{tabular}{|c|c|c|c|c|}
\hline & Total & Females & Males & $T(d f)$ \\
\hline \multirow[t]{2}{*}{$\mathrm{N}$} & 2,491 & 1,324 & $\mathrm{I}, 167$ & \\
\hline & $M(S D)$ & M (SD) & $M(S D)$ & \\
\hline Age & $48.3(18.2)$ & $48.8(18.1)$ & $47.8(18.4)$ & I.4 (2,489) \\
\hline Pain & $M(S D)$ & $M(S D)$ & $M(S D)$ & \\
\hline POLO pain scale $(\min 0, \max 10)$ & $0.82(\mathrm{I} .07)$ & $0.95(1.20)$ & $0.66(0.89)$ & $7.3(2,489)^{* * *}$ \\
\hline Bodily pain $(\min 0, \max 10)$ & $0.60(0.99)$ & $0.70(1.12)$ & $0.49(0.80)$ & $5.5(2,482)^{* * *}$ \\
\hline Headache $(\min 0, \max 10)$ & $1.69(2.4 \mathrm{I})$ & $2.18(2.64)$ & $1.12(1.98)$ & II.4 $(2,485)^{* * * *}$ \\
\hline Pain in neck/back $(\min 0, \max 10)$ & $1.54(1.96)$ & $1.75(2.11)$ & $1.31(1.75)$ & $5.5(2,445)^{* * *}$ \\
\hline Adverse childhood events & $\mathrm{N}(\%)$ & $\mathrm{N}(\%)$ & $\mathrm{N}(\%)$ & $\mathrm{Chi}^{2}(\mathrm{df})$ \\
\hline Bullying at school & $270(10.8)$ & $161(12.0)$ & III (9.5) & $4.1(I)^{*}$ \\
\hline CTQ - emotional abuse & $161(6.5)$ & $115(8.6)$ & $48(4 . I)$ & $20.6(\mathrm{I}) * * *$ \\
\hline CTQ - physical abuse & $163(6.5)$ & $86(6.4)$ & $81(6.9)$ & $0.3(\mathrm{I})$ \\
\hline CTQ - sexual abuse & $184(7.4)$ & $150(11.2)$ & $40(3.4)$ & $52.8(\mathrm{I})^{* * * *}$ \\
\hline CTQ - emotional neglect & $326(13.1)$ & $186(13.9)$ & $146(12.5)$ & $1.2(1)$ \\
\hline CTQ - physical neglect & $557(22.4)$ & $292(21.8)$ & $270(23.1)$ & $0.5(I)$ \\
\hline No abuse/neglect & $\mathrm{I}, 7 \mathrm{II}(68.7)$ & $891(66.5)$ & $824(70.4)$ & $2.4(1)$ \\
\hline One form of abuse/neglect & $4 I I(16.5)$ & $216(16.1)$ & $200(17.1)$ & $0.3(1)$ \\
\hline Two forms of abuse/neglect & $172(6.9)$ & $102(7.6)$ & $7 I(6 . I)$ & $2.5(1)$ \\
\hline Three forms of abuse/neglect & $90(3.6)$ & $52(3.9)$ & $39(3.3)$ & $0.5(1)$ \\
\hline Four forms of abuse/neglect & $51(2.0)$ & $32(2.4)$ & $21(1.8)$ & $1.3(\mathrm{I})$ \\
\hline Five forms of abuse/neglect & $29(1.2)$ & $22(1.6)$ & $8(0.7)$ & $4.5(1)^{*}$ \\
\hline Depression scores & $0.7(\mathrm{I} . \mathrm{I})$ & $0.8(1.2)$ & $0.6(1.1)$ & $4.6(2,474)^{* * *}$ \\
\hline Anxiety scores & $0.7(1.1)$ & $0.8(1.2)$ & $0.5(1.0)$ & $5.9(2,48 \mathrm{I})^{* * *}$ \\
\hline
\end{tabular}

Note: $* P<.05, * * * P<.001$.

Abbreviations: CTQ, Childhood Trauma Questionnaire; M, mean; max, maximum; min, minimum; N, number of participants; POLO, Polytrauma Outcome; T, t-test value; $d f$, degrees of freedom.

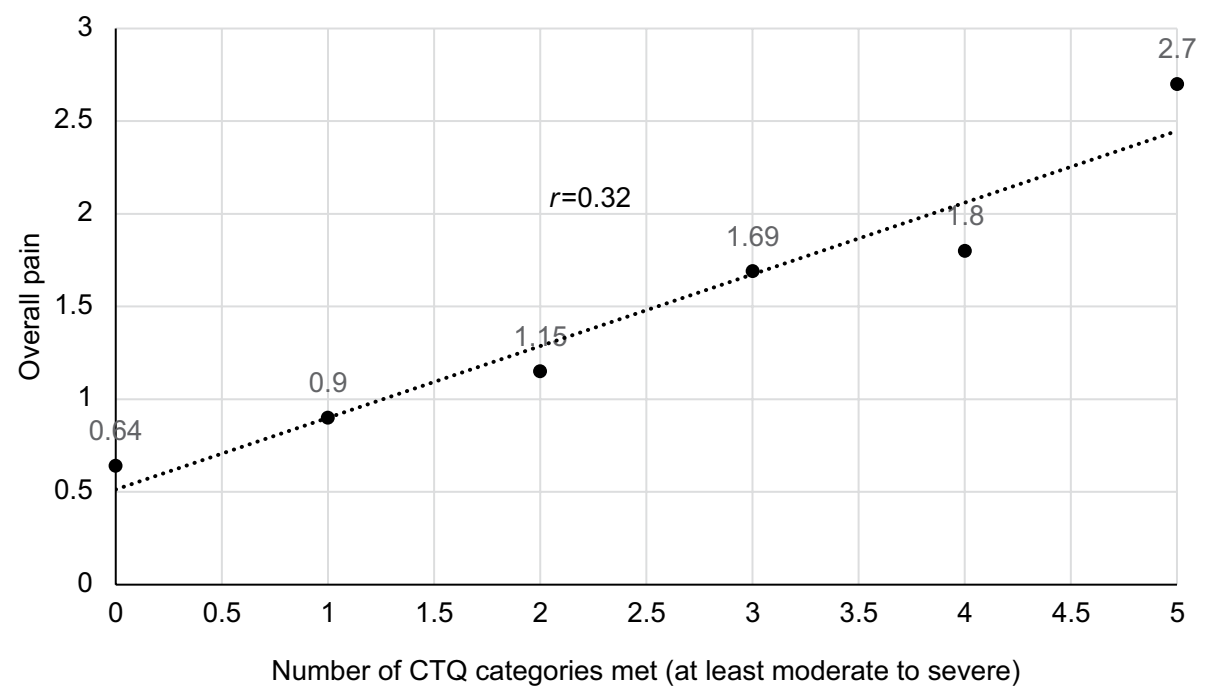

Figure I Correlation of POLO pain scale scores and number of experienced forms of childhood maltreatment or neglect.

Abbreviations: CTQ, Childhood Trauma Questionnaire; POLO, Polytrauma Outcome.

overall pain, as well as bodily pain, headaches, and back/neck pain (Table 2). Large effects were seen for emotional abuse on all types of pain, and for physical and sexual abuse on overall pain and bodily pain. Small effects were found for emotional and physical neglect on headaches and back/neck pain, while all other effects were in a medium range (for details see Table 2). 


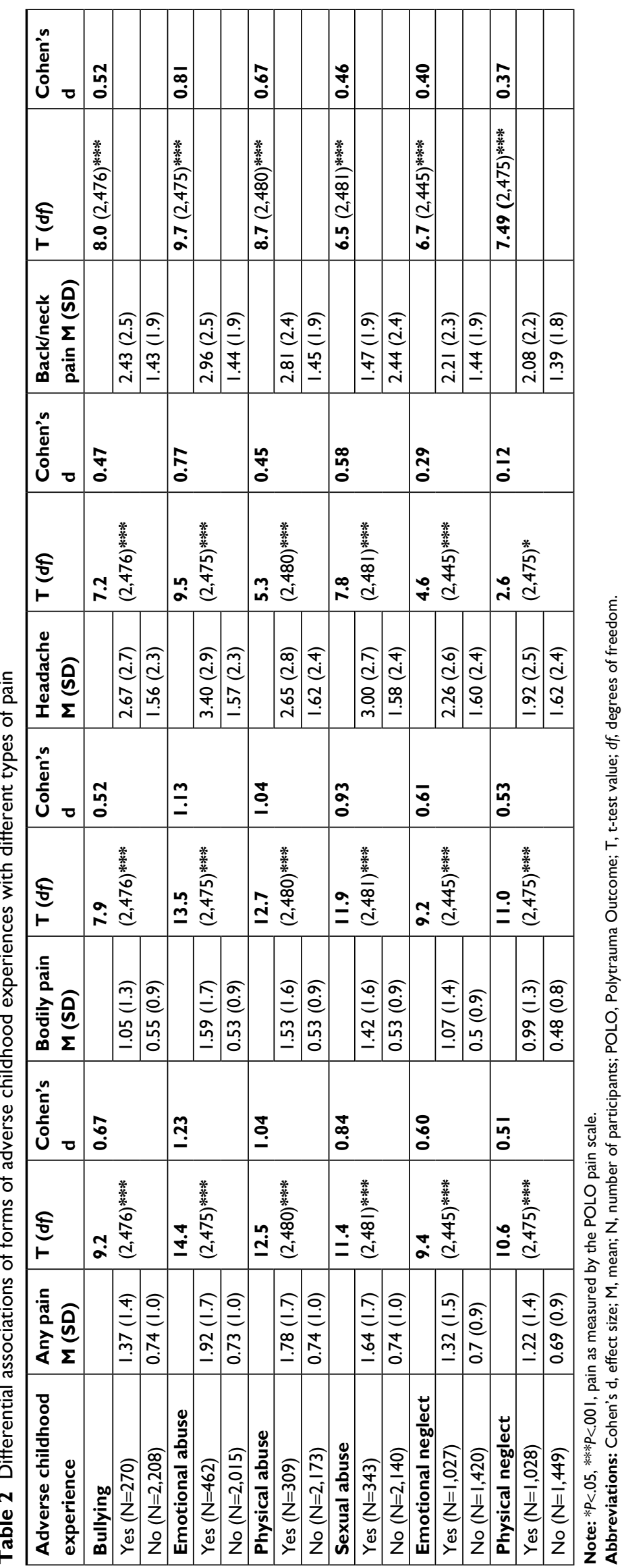




\section{Effect of childhood abuse, neglect, and peer bullying controlled for current symptoms of anxiety and depression, gender, and age}

A regression model including all five forms of maltreatment as measured dimensionally by the CTQ, bullying by peers (dichotomous), current anxiety and depression symptoms (as measured by the PHQ-2 and the GAD-2), age, and gender explained $28.6 \%$ of the variance of the POLO-physical state domain for pain (adjusted $\mathrm{R}^{2}=0.286$ ). All types of abuse, physical neglect, and bullying were positively associated with the experience of pain (Table 3), while emotional neglect was not. Even though depression/anxiety scores alone explained $10.5 \%$ of the variance and had the largest association overall, they did not significantly affect the impact of adverse childhood experiences on the experience of pain.

The significantly negative association of emotional neglect might be due to other variables explaining much more variance in the regression model, as $t$-tests showed enhanced pain levels in those participants reporting emotional neglect (Table 2), and an additional regression analysis performed only with participants who had only experienced emotional neglect $(\mathrm{N}=48)$ showed a positive (standardized $\mathrm{B}=0.17)$ but non-significant $(P=0.29)$ association with pain levels.

In order to test for a possible cumulative effect of experiencing different types of childhood maltreatment, but to reduce multicollinearity, a separate regression model including the number of experienced maltreatment categories was performed. The linear regression model further included a variable containing the numbers of categories met in the CTQ (at least moderate to severe), instead of individual CTQ categories, as well as bullying by peers, current anxiety and depression symptoms, age, and gender, explained $26.9 \%$ of

Table 3 Linear regression analyses with dependent variable POLO-physical state domain for pain $(\mathrm{N}=2,419)$

\begin{tabular}{|l|l|l|l|}
\hline Variable & Standardized B & T & P-value \\
\hline Emotional abuse & 0.09 & 3.42 & 0.001 \\
\hline Physical abuse & 0.08 & 3.47 & 0.00 I \\
\hline Sexual abuse & 0.09 & $4.3 \mathrm{I}$ & $<0.00 \mathrm{I}$ \\
\hline Emotional neglect & -0.06 & -2.64 & 0.008 \\
\hline Physical neglect & 0.07 & 3.05 & 0.002 \\
\hline Bullying & 0.06 & 3.19 & $0.00 \mathrm{I}$ \\
\hline Anxiety scores & 0.19 & 6.82 & $<0.00 \mathrm{I}$ \\
\hline Depression scores & 0.19 & 7.17 & $<0.00 \mathrm{I}$ \\
\hline Gender & 0.07 & 4.06 & $<0.00 \mathrm{I}$ \\
\hline Age & 0.13 & 7.46 & $<0.001$ \\
\hline
\end{tabular}

Note: Standardized B, standardized regression coefficient.

Abbreviations: POLO, Polytrauma Outcome; $T$, t-test value. the variance of the POLO-physical state domain for pain (adjusted $R^{2}=0.269$ ). In this model, all entered variables were significantly positively associated with pain scores (numbers of categories met in the CTQ: standardized $\mathrm{B}=0.16, P<0.001$, $t=8.77$; bullying: standardized $\mathrm{B}=0.08, P<0.001, t=4.29$ ).

\section{Differential effects by gender}

Generally, women reported significantly higher levels of pain and higher levels of emotional abuse and sexual abuse than men, but not for other types of abuse. Women also stated to have been bullied slightly more often than men and reported significantly higher levels of anxiety and depression (for details see Table 1). Therefore, two separate linear regression models were entered for male and female participants. The same variables as for the overall sample were entered. While in women emotional abuse, physical abuse, sexual abuse, physical neglect, and bullying were positively associated with the experience of pain, only physical and sexual abuse were significantly predictive in men (Table 4). Again, the significantly negative association of emotional neglect in women might be due to other variables explaining much more variance in the regression model.

In order to test for a possible cumulative effect of experiencing different types of childhood maltreatment, but to reduce multicollinearity, separate regression models including the number of experienced maltreatment categories were performed (for a more extensive description see above). In both, men and women, number of experienced types of childhood maltreatment were significantly associated with levels of pain (standardized $\mathrm{B}_{\text {males }}=0.17, P<0.001, t=6.14$; standardized $\left.\mathrm{B}_{\text {females }}=0.16, P<0.001, t=6.09\right)$. However, while bullying was still significantly associated with pain in women ( standardized $\mathrm{B}_{\text {females }}=0.10, P<0.001, t=4.04$ ), it was not in men (standardized $\mathrm{B}_{\text {males }}=0.04, P=0.16, t=1.42$ ).

\section{Discussion}

In this study based on a representative sample of the German population, adverse childhood experiences were significantly linked to the experience of pain in adulthood. As most studies so far have been investigating this relationship in clinical samples, or populations with a history of abuse, the current study adds to the literature by providing data from the general population, on participants with mainly non-clinical levels of pain. Interestingly, adverse childhood experiences still were significantly associated with experiences of pain over and above current symptoms of depression and anxiety. However, depression and anxiety scores were associated significantly with pain experiences. These results are in line 
Table 4 Separate regression analyses by gender with dependent variable POLO-physical state domain for pain

\begin{tabular}{|c|c|c|c|c|c|c|}
\hline \multirow[b]{2}{*}{ Variable } & \multicolumn{3}{|c|}{ Female (adjusted $R^{2}=0.30, N=I, 309$ ) } & \multicolumn{3}{|c|}{ Male (adjusted $R^{2}=0.23 ; \mathrm{N}=\mathrm{I}, \mathrm{I} 52$ ) } \\
\hline & Standardized B & $\mathbf{T}$ & $P$-value & Standardized B & $\mathbf{T}$ & P-value \\
\hline Emotional abuse & 0.15 & 4.08 & $<0.001$ & -0.02 & -0.50 & 0.616 \\
\hline Physical abuse & 0.08 & 2.52 & 0.012 & 0.11 & 3.06 & 0.002 \\
\hline Sexual abuse & 0.08 & 2.93 & 0.003 & 0.07 & 2.51 & 0.012 \\
\hline Emotional neglect & -0.14 & -4.16 & $<0.001$ & 0.04 & 1.13 & 0.26 \\
\hline Physical neglect & 0.09 & $2.8 I$ & 0.005 & 0.07 & 1.86 & 0.06 \\
\hline Bullying & 0.10 & 2.84 & 0.005 & 0.04 & 1.26 & 0.21 \\
\hline Anxiety scores & 0.20 & 5.30 & $<0.001$ & 0.16 & 3.88 & $<0.001$ \\
\hline Depression scores & 0.20 & 5.28 & $<0.001$ & 0.21 & 5.19 & $<0.001$ \\
\hline Age & 0.14 & 5.63 & $<0.001$ & 0.14 & 4.95 & $<0.001$ \\
\hline
\end{tabular}

Notes: Standardized B, standardized regression coefficient. Bold values are significant results regarding childhood maltreatment.

Abbreviations: POLO, Polytrauma Outcome; T, t-test value.

with results from a sample of the general population from the US $(\mathrm{N}=1.727)$, describing sexual and physical abuse, as well as symptoms of depression to be significantly, but independently, associated with experiences of pain ${ }^{10}$ and a study including German patients with fibromyalgia syndrome only finding partially mediating effects of depression and childhood maltreatment. ${ }^{34}$ Furthermore, the relationship between childhood maltreatment, depression, and pain is likely to be rather complex, with childhood maltreatment influencing both the development of depressive symptoms and pain. Pain can lead to the development of depressive and anxiety symptoms, but can also represent an affective component and is therefore likely to be influenced by depressive and anxiety symptoms vice versa.

Comparable to another study using the CTQ to measure childhood maltreatment,$^{20}$ we found significant associations between the number of forms of childhood maltreatment and severity of pain. Interestingly, a regression model containing all different types of maltreatment explained a similar part of the variance of scores on the POLO pain scale as a regression model only containing the number of different types of childhood maltreatment experienced. These results underline a dose-response effect of childhood maltreatment, as found in previous studies. ${ }^{9,18,20,21}$ This effect might be due to an additive effect of stress related to several adverse childhood experiences, thus leading to an even more pronounced detrimental effect on the developing brain and associated neurophysiological mechanisms..$^{35}$

While physical and sexual abuse, physical neglect, and bullying were significantly associated with pain levels in the regression model, emotional abuse showed particularly high effect sizes for all types of pain (ie, bodily pain, back pain, and headaches) when comparing participants with and without specific adverse childhood experiences. Especially, the pronounced effect on headaches corresponds well to results of a study reporting specifically high prevalence rates of emotional abuse in a sample of migraine patients. ${ }^{15}$ This is a particularly interesting finding, as types of abuse involving the body (physical and sexual abuse) showed particularly high effects on bodily pain, while emotional abuse resulted in more general effects on pain across the body. Similar as in a study of a community-based sample from Japan, physical abuse had a significant effect on bodily and back/neck pain, while sexual abuse was rather associated with any pain than back/neck pain. ${ }^{9}$

While most studies have so far focused on maltreatment by family members, our study also showed adverse effects of being bullied by peers. This form of interpersonal violence was therefore significantly related to pain independently of family-related adverse experiences. A longitudinal study showed significant effects of being bullied as an adolescent on the experience of pain in young adulthood $;{ }^{23}$ however, those results were not controlled for adverse experiences within the family. As a Dutch study found significant results of bullying on the experience of chronic pain in adolescents who were independent of parental physical and sexual abuse, ${ }^{22}$ our study adds on to those findings by extending the effect to adulthood and by also showing an independent effect besides emotional abuse and neglect by family members. Interestingly, the effect of bullying on pain was independent from adverse experiences within the family in women, but not in men. This is in line with studies investigating adverse psychosocial outcomes of being bullied, finding stronger effects in girls than in boys ${ }^{36}$ even lasting into adulthood. ${ }^{37}$ Reasons for those differences might be that girls are more often victims of relational bullying (such as ostracism), while boys are more often victims of direct, physical forms of bullying. As relational bullying seems to have generally more 
devastating long-term effects, women might suffer long-term effects from childhood bullying more frequently than men. Furthermore, biological factors such as differences in the serotonin system may be involved. ${ }^{37}$ However, since type of bullying and biological measures were not assessed in the current study, these interpretations would have to be clarified in future studies. In general, these results underline the importance of prevention of bullying in schools and supplying recreational settings, especially given the high prevalence rates of bullying among youth. ${ }^{38}$

When analyzing data separately for women and men, differential effects were found. While almost all forms of maltreatment and bullying had a significant effect on the experience of pain in women, only physical and sexual abuse showed a significant effect in men. These findings could underline a higher vulnerability of females to early lifetime stressors due to differential developmental processes. ${ }^{24}$ However, as women generally reported higher levels of pain, childhood maltreatment, and bullying in the current sample, the results may also be an effect of higher variability in the female sub-sample.

In light of the aforementioned evidence, the association between the experience of adverse childhood events and pain later in life seems to be well established and is further supported by data from our study of a representative population sample. It is therefore of interest to further elucidate the origin of this link. It may well be that this link is caused by a general increase in detrimental health conditions. Adverse childhood experiences increase the risk of developing physical health impairment later on in life (for review see Norman et $\mathrm{al}^{26}$ ) and thus the increase in pain might be due to impaired health conditions causing pain. The link between adverse childhood experiences and pain can also be understood from a neurobiological viewpoint as it has been shown that regions of the brain involved in the pain matrix (such as the anterior cingulate cortex, the amygdala, or the hippocampus) are altered after experiences of childhood abuse and trauma, ${ }^{39}$ with regions especially involved in the affective processing of pain being altered in functioning after physical and sexual abuse. ${ }^{40}$ With regard to bullying, it has recently been shown that adolescents who feel socially excluded activate regions involved in the pain matrix, ${ }^{41}$ a finding linking to the large literature of "social pain". ${ }^{42}$ It is likely that both on a neurobiological level and an immunomodulatory level, a complex interplay is responsible for the increase in pain as well as for impaired physical health conditions. Further studies focusing on these mechanisms are needed to understand this interplay with the potential benefit of being able to prevent detrimental consequences for survivors of adverse childhood experiences.

\section{Limitations of the study}

Since this was a cross-sectional study, no interpretations on causality can be made. As in all retrospective studies, results of this study may have been biased by recall biases with regard to reports on childhood maltreatment and bullying. However, results measured by the CTQ in representative samples of the German population seem to be rather reliable, as shown in a recent study comparing two samples from 2011 and 2016. ${ }^{43}$ Bullying was only assessed by one question, which did not specify the age in which bullying occurred during childhood and what type of bullying was experienced. Therefore, results on bullying need to be interpreted with care, as the validity of this question is not known. Furthermore, levels of pain in this non-clinical sample were expectedly rather low (around 1 on a scale from 0 to 10 ), thus possibly not providing a large enough variance in data to detect all possible effects. Pain and bullying were administered by scales without previously published psychometric properties. No differentiation between the experience of acute and chronic pain in participants can be made, as they were asked to indicate their experiences with pain within the past 7 days (which may have been chronic or acute). Therefore, effects found in this study have to be interpreted with care concerning the state-dependency of reported levels of pain. As this was a study including a large sample and focusing on psychological measures, no funds were available to collect neurobiological data. Despite these limitations, effect sizes found in this study were rather large.

\section{Conclusion}

Adverse childhood experience seems to have a long-lasting effect on the experience of pain in the general population in Germany. This was specifically true for emotional, physical, and sexual abuse. Apart from maltreatment by family members, bullying by peers during childhood was also significantly related to pain. While symptoms of depression and anxiety were strongly related to the experience of pain, they did not affect the relationship between adverse childhood experiences and pain. These results underline the necessity of prevention of childhood maltreatment and bullying, as adverse long-term effects can not only be seen in clinical samples but even in the general population.

\section{Author contributions}

RCB and PLP take responsibility for the integrity of the work as a whole, from inception to published article. PLP, MHL, and JMF designed the study; JMF and EB acquired the data; and $\mathrm{RCB}$ analyzed and interpreted the data. RCB and PLP drafted the manuscript, and all the authors revised it critically 
for important intellectual content. All the authors approved the final version to be published. All authors contributed toward data analysis, drafting and critically revising the paper and agree to be accountable for all aspects of the work.

\section{Disclosure}

PLP received research funding from Bundesinstitut für Arzneimittel und Medizinprodukte, BMBF (Federal Ministry of Education and Research), VW-Foundation, Baden-Württemberg Stiftung, Lundbeck, Servier. He holds no stocks of pharmaceutical companies. JMF received research funding from the EU, DFG (German Research Foundation), BMG (Federal Ministry of Health), BMBF (Federal Ministry of Education and Research), BMFSFJ (Federal Ministry of Family, Senior Citizens, Women and Yottemberg Stiftung, Lundbeck, Servier. uth), German armed forces, several state ministries of social affairs, State Foundation Baden Württemberg, Volkswagen Foundation, European Academy, Pontifical Gregorian University, RAZ, CJD, Caritas, Diocese of Rottenburg Stuttgart. Moreover, he received travel grants, honoraria, and sponsoring for conferences and medical educational purposes from $\mathrm{DFG}$, AACAP, NIMH/NIH, EU, Pro Helvetia, Janssen Cilag (J\&J), Shire, several universities, professional associations, political foundations, and German federal and state ministries during the last 5 years. JMF conducts clinical investigations and consultancy work for Servier, BMBF and Lundbeck. Every grant and every honorarium have to be declared to the law office of the University Hospital Ulm and to the DGKJP and AACAP. Professor Fegert holds no stocks of pharmaceutical companies and gives no lectures sponsored by the industry. The other authors report no conflicts of interest in this work.

\section{References}

1. Breivik H, Collett B, Ventafridda V, Cohen R, Gallacher D. Survey of chronic pain in Europe: prevalence, impact on daily life, and treatment. Eur J Pain. 2006;10(4):287-333.

2. Merskey H, Bogduk N. Classification of Chronic Pain. Description of Chronic Pain Syndromes and Definition of Pain Terms. 2nd ed. Seatlly, WA: IASP Press; 1994.

3. Ballard E, Bosk A, Pao M. Invited commentary: understanding brain mechanisms of pain processing in adolescents' non-suicidal self-injury. J Youth Adolesc. 2010;39(4):327-334.

4. Holley AL, Wilson AC, Noel M, Palermo TM. Post-traumatic stress symptoms in children and adolescents with chronic pain: A topical review of the literature and a proposed framework for future research. Eur J Pain. 2016;20(9):1371-1383.

5. Coppens E, Van Wambeke P, Morlion B, et al. Prevalence and impact of childhood adversities and post-traumatic stress disorder in women with fibromyalgia and chronic widespread pain. Eur J Pain. 2017;21(9):1582-1590.

6. Häuser W, Hoffmann EM, Wolfe F, et al. Self-reported childhood maltreatment, lifelong traumatic events and mental disorders in fibromyalgia syndrome: a comparison of US and German outpatients. Clin Exp Rheumatol. 2015;33(1 Suppl 88):S86-S92.
7. Hellou R, Häuser W, Brenner I, et al. Self-Reported Childhood Maltreatment and Traumatic Events among Israeli Patients Suffering from Fibromyalgia and Rheumatoid Arthritis. Pain Res Manag. 2017:3865249.

8. Häuser W, Galek A, Erbslöh-Möller B, et al. Posttraumatic stress disorder in fibromyalgia syndrome: prevalence, temporal relationship between posttraumatic stress and fibromyalgia symptoms, and impact on clinical outcome. Pain. 2013;154(8):1216-1223.

9. Stickley A, Koyanagi A, Kawakami N; WHO World Mental Health Japan Survey Group. Childhood adversities and adult-onset chronic pain: Results from the World Mental Health Survey, Japan. Eur J Pain. 2015;19(10):1418-1427.

10. Sachs-Ericsson N, Kendall-Tackett K, Hernandez A. Childhood abuse, chronic pain, and depression in the National Comorbidity Survey. Child Abuse Negl. 2007;31(5):531-547.

11. Brown J, Berenson K, Cohen P. Documented and self-reported child abuse and adult pain in a community sample. Clin J Pain. 2005;21(5):374-377.

12. Davis DA, Luecken LJ, Zautra AJ. Are reports of childhood abuse related to the experience of chronic pain in adulthood? A meta-analytic review of the literature. Clin J Pain. 2005;21(5):398-405.

13. Häuser W, Glaesmer H, Schmutzer G, Brähler E. Widespread pain in older Germans is associated with posttraumatic stress disorder and lifetime employment status-results of a cross-sectional survey with a representative population sample. Pain. 2012;153(12):2466-2472.

14. Walsh CA, Jamieson E, Macmillan H, Boyle M. Child abuse and chronic pain in a community survey of women. J Interpers Violence. 2007;22(12):1536-1554.

15. Tietjen GE, Brandes JL, Peterlin BL, et al. Childhood maltreatment and migraine (part II). Emotional abuse as a risk factor for headache chronification. Headache. 2010;50(1):32-41.

16. Herrenkohl RC, Herrenkohl TI. Assessing a child's experience of multiple maltreatment types: Some unfinished business. J Fam Violence. 2009;24(7):485.

17. Witt A, Brown RC, Plener PL, Brähler E, Fegert JM. Child maltreatment in Germany: prevalence rates in the general population. Child Adolesc Psychiatry Ment Health. 2017;11:47.

18. Tietjen GE, Brandes JL, Peterlin BL, et al. Childhood maltreatment and migraine (part III). Association with comorbid pain conditions. Headache. 2010;50(1):42-51.

19. Arnow BA, Hart S, Hayward C, Dea R, Barr Taylor C. Severity of child maltreatment, pain complaints and medical utilization among women. J Psychiatr Res. 2000;34(6):413-421.

20. Steine IM, Winje D, Krystal JH, et al. Cumulative childhood maltreatment and its dose-response relation with adult symptomatology: Findings in a sample of adult survivors of sexual abuse. Child Abuse Negl. 2017;65:99-111.

21. Le MT, Holton S, Nguyen HT, Wolfe R, Fisher J. Victimisation, polyvictimisation and health-related quality of life among high school students in Vietnam: a cross-sectional survey. Health Qual Life Outcomes. 2016;14(1):155.

22. Voerman JS, Vogel I, de Waart F, et al. Bullying, abuse and family conflict as risk factors for chronic pain among Dutch adolescents. Eur J Pain. 2015;19(10):1544-1551.

23. Sigurdson JF, Wallander J, Sund AM. Is involvement in school bullying associated with general health and psychosocial adjustment outcomes in adulthood? Child Abuse Negl. 2014;38(10):1607-1617.

24. Ganguly P, Brenhouse HC. Broken or maladaptive? Altered trajectories in neuroinflammation and behavior after early life adversity. Dev Cogn Neurosci. 2015;11:18-30.

25. Tofoli SMC, Baes CVW, Martins CMS, Juruena M. Early life stress, HPA axis, and depression. Psychol Neurosci. 2011;4(2):229-234.

26. Norman RE, Byambaa M, De R, Butchart A, Scott J, Vos T. The long-term health consequences of child physical abuse, emotional abuse, and neglect: a systematic review and meta-analysis. PLoS Med. 2012;9(11):e1001349.

27. McWilliams LA, Goodwin RD, Cox BJ. Depression and anxiety associated with three pain conditions: results from a nationally representative sample. Pain. 2004;111(1-2):77-83. 
28. Klinitzke G, Romppel M, Häuser W, Brähler E, Glaesmer H. The German Version of the Childhood Trauma Questionnaire (CTQ): psychometric characteristics in a representative sample of the general population. Psychother Psychosom Med Psychol. 2012;62(2):47-51. German.

29. Wingenfeld K, Spitzer C, Mensebach C, et al. The German version of the Childhood Trauma Questionnaire (CTQ): preliminary psychometric properties. Psychother Psychosom Med Psychol. 2010;60(11) $442-450$.

30. Häuser W, Schmutzer G, Brähler E, Glaesmer H. Maltreatment in childhood and adolescence: results from a survey of a representative sample of the German population. Dtsch Arztebl Int. 2011;108(17): 287-294.

31. Pirente N, Bouillon B, Schäfer B, et al. [Systematic development of a scale for determination of health-related quality of life in multiple trauma patients. The Polytrauma Outcome (POLO) Chart]. Unfallchirurg. 2002;105(5):413-422. German.

32. Löwe B, Kroenke K, Gräfe K. Detecting and monitoring depression with a two-item questionnaire (PHQ-2. J Psychosom Res. 2005;58(2):163-171.

33. Kroenke K, Spitzer RL, Williams JB, Monahan PO, Löwe B. Anxiety disorders in primary care: prevalence, impairment, comorbidity, and detection. Ann Intern Med. 2007;146(5):317-325.

34. Häuser W, Bohn D, Kühn-Becker H, Erdkönig R, Brähler E, Glaesmer $H$. Is the association of self-reported childhood maltreatments and adult fibromyalgia syndrome attributable to depression? A case control study. Clin Exp Rheumatol. 2012;30(6 Suppl 74):59-64.
35. Dube SR, Fairweather D, Pearson WS, Felitti VJ, Anda RF, Croft JB. Cumulative childhood stress and autoimmune diseases in adults. Psychosom Med. 2009;71(2):243-250.

36. van der Wal MF, de Wit CA, Hirasing RA. Psychosocial health among young victims and offenders of direct and indirect bullying. Pediatrics. 2003;111(6 Pt 1):1312-1317.

37. Sourander A, Ronning J, Brunstein-Klomek A, et al. Childhood bullying behavior and later psychiatric hospital and psychopharmacologic treatment: findings from the Finnish 1981 birth cohort study. Arch Gen Psychiatry. 2009;66(9):1005-1012.

38. Barzilay S, Brunstein Klomek A, Apter A, et al. Bullying Victimization and Suicide Ideation and Behavior Among Adolescents in Europe: A 10-Country Study. J Adolesc Health. 2017;61(2):179-186.

39. Teicher MH, Andersen SL, Polcari A, Anderson CM, Navalta CP, Kim DM. The neurobiological consequences of early stress and childhood maltreatment. Neurosci Biobehav Rev. 2003;27(1-2):33-44.

40. Ringel Y, Drossman DA, Leserman JL, et al. Effect of abuse history on pain reports and brain responses to aversive visceral stimulation: an FMRI study. Gastroenterology. 2008;134(2):396-404.

41. Groschwitz RC, Plener PL, Groen G, Bonenberger M, Abler B. Differential neural processing of social exclusion in adolescents with non-suicidal selfinjury: An fMRI study. Psychiatry Res Neuroimaging. 2016;255:43-49.

42. Eisenberger NI, Lieberman MD, Williams KD. Does rejection hurt? An FMRI study of social exclusion. Science. 2003;302(5643):290-292.

43. Witt A, Glaesmer H, Jud A, et al. Trends in child maltreatment in Germany: comparison of two representative population-based studies. Child Adolesc Psychiatry Ment Health. 2018;12(1):24.
Journal of Pain Research

\section{Publish your work in this journal}

The Journal of Pain Research is an international, peer reviewed, open access, online journal that welcomes laboratory and clinical findings in the fields of pain research and the prevention and management of pain. Original research, reviews, symposium reports, hypothesis formation and commentaries are all considered for publication.

\section{Dovepress}

The manuscript management system is completely online and includes a very quick and fair peer-review system, which is all easy to use. Visit http://www.dovepress.com/testimonials.php to read real quotes from published authors. 